\title{
Studies on Effect Process Parameters on Cutting Force and Surface Integrity in End Milling with Nano Fluids as Coolant
}

\author{
P. Palanisamy \\ Faculty, Department of Mechanical Engineering, \\ Saveetha Engineering College, \\ Thandalam,Chennai
}

\author{
J. Shanthi \\ Assistant Engineer, \\ Mettur Thermal Power Station, Mettur, \\ Salem, TN
}

\author{
N. P. Manojkumar \\ Department of Mechanical Engineering, \\ Knowledge Institute of Technology, \\ Salem, TN, India
}

\begin{abstract}
Milling is a cutting process widely used in manufacturing industries. During the cutting process larger amount of heat is generated. If the heat generated in milling is not dissipated, it may lead to reduce tool's life, poor surface finish of machined face and thereby the overall performance of the machining process is condensed. In this work, MWCNT/water nano fluid is used as coolant to carry away the heat generated. The objective of this work is to deal with the effect of cutting parameters such as cutting speed, feed and depth of cut on surface roughness in End Milling while using nano fluids as coolant. An Artificial Neural Network ANN model has also been developed to predict the cutting force taking cutting speed, feed depth of cut and nose radius as input parameters. Experiments have been made on a CNC milling machine while milling of EN 24 steel using $20 \mathrm{~mm}$ an uncoated tungsten carbide end mill cutter (ISO designation P20 grade, axial rake angle $=+\mathbf{1 8}^{\circ}$ ) with $\mathrm{MWCNT} /$ water nano fluids as coolant. The study covers the use of nano fluids and their effect on both workpiece and cutting tools including surface roughness and cutting force have been explained. The surface roughness improvement was about $20 \%$ while using nano fluid coolant. As a result, the paper is a roadmap for the researchers and practitioners during while machining using nano cutting fluid as coolant.
\end{abstract}

Keywords - End-Milling, Cutting parameters, Design of Experiments, cutting force, Nanofluid

\section{INTRODUCTION}

Milling is the mainly common form of machining. The main needs of consumer are quality metal cutting related products, which drives the metal cutting industry to continuously improve quality control of the metal cutting processes and minimises wear, is one of the ways for an industry to reduce its manufacturing cost. There has been increased interest in monitoring all the metal cutting processes. Hence the process parameters such as cutting speed, depth of cut, feed rate and nose radius have to be controlled and should be kept within the permissible limits of cutting force for any manufacturing process. In order to maximise their gains, an accurate process model must be developed taking cutting speed, feed, depth of cut and nose radius as input machining parameters and cutting force as output parameters. Experiments have been made based on the Design of Experiments at five levels and four factors full factorial technique. The cutting forces have been measured using three axis milling tool dynamometer. The ANN model has been obtained by training the network in MATLAB with the measured values.

\section{LITERATURE SURVEY}

Abrari et al., [1] have developed a dynamic force model and a stability analysis of ball end milling. The concept of orthogonal metal cutting conditions, which they applied to modeling the mechanics of ball end milling, can be used to determine cutting forces. Ginting and Nouari [2] have studied the cutting conditions for end milling of aeroengine material Ti6242S under dry condition. Lee and Ko [3] have hinted that Fy force at all depths of cut has been observed to be approximately $30 \%$ higher than Fx force. They deduce the tendency while using down milling at high axial depths of cut that tends to result in an over cut on the workpiece due to its higher Fy. Palanisamy et al. [4] have developed a cutting force model for end milling to predict tangential cutting force and thrust force. They have also studied the thermal effect on cutting force. Radhakrishnan et.al [5] have presented a regression model using the experimental data and developed an ANN model. Kaymakci et al. [6] have developed a unified cutting mechanics model to predict the forces in milling, turning, boring and drilling operations.

Kovacic et al, [7] have developed genetic programming to determine cutting-forces in milling. Baskar et al. [8] have presented the optimized cutting parameters for milling operation. Palanisamy et al. [9] have presented an ANN model for prediction of tool wear and surface roughness. Subramanian et.al [10] have proposed a statistical model to determine cutting force and optimized the parameters for 3 input parameters. Ganesh Babu et al. [11] have studied the effects of machining parameters on the variations of cutting forces in end milling operation of $\mathrm{Al} \mathrm{SiC} \mathrm{metal} \mathrm{matrix}$ composite material. They have shown the cutting force in tangential direction increases when increase in depth of cut. Liong et al [12] have developed a new method called Free Pattern Search (FPS) to predict the surface roughness by using an explicit model. FPS takes the advantage of the 
expression tree in Gene Expression Programming (GEP) to encode the solution and express a non-determinative tree using a fixed length individual. FPS is inspired by Pattern Search (PS) and hybrid scatter manipulator to keep the population diversity. Siluver.saravanthi et (al) [13] have optimized parameter values that are determined using Taguchi method and regression analysis. The cutting parameters used for operation are cutting speed, depth of cut and federate while milling of aluminum alloy. The dependence of cutting force coefficients on milling process parameters, including feed per tooth, spindle speed, and radial immersion by using linear regression method and non linear optimization method has been developed by Mark et.al [14]. Palanisamy et al. [15] have developed regression and ANN models for prediction of tool wear in end-milling operations while machining of AISI 1020 steel using carbide cutter by considering only three machining parameters such as cutting speed, depth of cut and feed rate.

It is understood from the literature; it exposes that much work has not been stated on prediction of cutting force and surface roughness using nano-fluids in end mill. So, an accurate cutting force model is needed. In this work, the main objective is to develop an ANN model based on measured cutting values taking 4 machining parameters such as cutting speed, cutting feed rate, axial depth of cut and nose radius while using nano fluids as coolant. Researchers have used many methods for the prediction of cutting force, but the use of ANN model has not been used so far for End milling by taking 4 parameters such as feed, cutting speed, depth of cut and nose radius. In order to increase the efficiency, it is quintessential to improve the understanding of the metal cutting process. The knowledge on cutting force is required to choose suitable and desirable cutting parameter and will also help the manufacturer in the design of machine tool structure and to select the power of the driving motor.

\subsection{Design of Experiments}

The use of experimental design to get the required information with minimum effort and time. Therefore, the experimental plan and program should be well prepared and designed to perform machining. Experimental design is a tool to aid the experimenter in coping with the complexities of the technical investigations.

\subsubsection{Identification of the Process Variables and Limits}

In this research work, the chosen input parameters which effect the tool wear and surface roughness are cutting speed (V1), feed rate (f1), depth of cut (b1) and nose radius (R1). They are selected as factors to carry out the experimental works and the development of models. The chosen responses are cutting force. The selected process parameters of the experiment for cutting force, with their limits, units and notations, are given in Table 1. The upper limit of the parameter is coded as +2 and the lower limit is coded -2 . The coded values for intermediate values have been calculated from the following relationship:

$$
X_{i}=\frac{2\left(2 X-\left(X_{\max }+X_{\min }\right)\right)}{\left(X_{\max }-X_{\min }\right)}
$$

Where, $\mathrm{X}_{\mathrm{i}}$ is the required coded value of a variable $\mathrm{X}, \mathrm{X}$ is any value of the variable from $X_{\min }$ to $X_{\max }, X_{\min }$ is the lower limit of the variable and $\mathrm{X}_{\max }$ is the upper limit of the variable.

\subsubsection{Development of Design Matrix}

Design matrix chosen to conduct the experiments is a central composite rotatable design. The design matrix comprises of full replica of $25(=32)$, Factorial designs. All cutting parameters in the intermediate levels $(0)$ constitute the central points and combination of each cutting parameters is either at the highest value $(+2)$ or the lowest value $(-2)$ with other parameters of intermediate levels $(0)$ creating star points. 32 experimental trails have been conducted that make the estimation of linear quadratic and two-way interactive effects of cutting parameters on tool wear and surface roughness.

\subsubsection{Conducting the Experiment as per the Design Matrix}

The experimental setup is shown in Fig. 1. The experiments have been conducted on a HASS vertical machining center on EN 48 steel material by using an uncoated tungsten carbide end mill (ISO designation P20 grade, axial rake angle $=+18^{\circ}$ ) and having a diameter of $20 \mathrm{~mm}$ with 4 flutes for different combination of cutting parameters by means of MWCNT/water nano fluids as coolant at Kumarguru College of Technology, Coimbatore, India.. The work piece is in the form of rectangular of $50 \mathrm{~mm} \times 30 \mathrm{~mm}$ in cross section and $200 \mathrm{~mm}$ in length of EN 28 steel to measure cutting forces such as infeed force, crossfeed force and thrust force by means of three axis Syscon milling tool dynamometer in accordance with the ISO standards 3688 [13]. The surface roughness has been measured with Mitutoyo surftester SJ 210. First part of 8 experiments has been conducted initially under dry cutting conditions and using MWCNT/water Nano fluid as coolant to study the effect of coolant. 32 experiments has been conducted as per design matrix using nano fluid coolant. The data attained in the data acquisition software for 32 experiments are presented in Table 2.

\section{NEURAL NETWORK MODEL}

\subsection{Feed Forward Back Propagation Algorithm}

ANNs consist of multiple nodes, which imitate biological neurons of human brain. The nodes can read the input data and perform simple operations on the data. The result of these operations is passed to next neurons. The output at each node is called its activation or node value. Each link is associated with weight. A feed forward back propagation network consists of three (3) layers namely, an input layer, at least one intermediate hidden layer, and an output layer. Back drop networks can adapt their weights to acquire knowledge. The training of the neural network adapting a feed-forward back propagation algorithm has been carried out. Then the error signals resulting from the difference between the computed and the actual are back propagated from the output layer to the previous layers for them to update their weights. The number of neurons in the hidden layer is intentionally chosen to start from one neuron and hidden neurons are added to the hidden layer incrementally. The addition of hidden neurons continues until there is no further improvement in network 
performance. Once the average error is less than the required goal, the neural network stops training and is, therefore, ready to be verified.

\subsection{Topology of Neural Network}

The architecture topology of feed-forward three-layered back propagation neural network consists of 3 layers which include the input, the hidden and the output layers. The ANN configuration is represented as $4: 3: 3$, that is the number of neurons in the input layer consists of cutting speed, feed, Depth of Cut and nose radius, which are used to assess the cutting force. The number of neurons in the hidden layer is determined by training many different neural networks, but finally three hidden neurons in a single hidden layer have been selected as an optimum number. There is no fixed rule for determining the number of neurons in the hidden layer. The number of neurons in this layer must be large enough to allow for enough partitions of the non-linear evaluation space. The number of output nodes is taken to be three, so as to indicate cutting forces in $\mathrm{x}, \mathrm{y} \& \mathrm{z}$ directions.

\subsection{Training the Network}

The model has been developed by means of MATLAB $2013 \mathrm{~b}$ for training the network to predict the cutting force. During the training phase, the values of weights must be initially and randomly preset in a chosen range; in this work, from 0 to 0.1 . Each neuron is a processing element, which performs a weighed sum of all input variables that feed it. Depending on the value of weighted sum of the variables, the neuron gives a signal to the neurons in the adjacent layer through a non-linear transfer function (sigmoid function in this case). The algorithm used for the neural network learning is 'the feed forward backward propagation algorithm'. So, the learning is an adaptive nature that means vector pairs from the training model are mapped respectively to reinforce the weights until deviation between the training output and the desired output of each training vector converges to a negligible error. The Simulink trained model was developed. The training parameters of ANN models used are given below:

Number of input nodes

Number of hidden nodes

Number of output nodes

Number of epochs

(maximum)

The accuracy of the model increases with increase of node in the hidden layer. In predicting cutting forces, the average error by the ANN model is less than $4 \%$. It is thus determined that the ANN model is found to be capable of better predictions of cutting forces accurately.

\section{RESULTS AND DISCUSSION}

- Fx is the cutting force along the feed of workpiece, while Fy is the cutting force normal to the feed of workpiece and $\mathrm{Fz}$ is the cutter axil force.

- $\quad$ Fig.3 shows the variation of cutting force in $\mathrm{X}$ and $\mathrm{Y}$ direction under dry and using MWCNT/water nanofluids as coolant with depth of cut. It is clear that the cutting force increases with the increase in depth of cut. When the depth of cut increases, the chipthickness increases. Hence the cutting force is increased.
- It is found that the variation of cutting force in $X$ and $\mathrm{Y}$ direction under dry and using MWCNT/water nanofluids as coolant with feed rate. The feed rate tends to increase the cutting force. This is because as the feed rate increases, the material removal volume per revolution increases. So, more energy is needed and thus increasing the cutting force. It is observed that the increasing in feed rate shows significant influence on cutting force.

- When employing down milling, Fy force at all depths of cut has been observed to be approximately 30\% higher than Fx force. Lee and Ko [3] have also made same observations when milling at higher axial depths of cut.

- It is found that using MWCNT/water nanofluids as coolant, the cutting forces reduction is very marginal about 3-4\%.

- An ANN model has been developed from the experimental values of cutting forces. The predicted cutting force obtained from ANN model has been compared with measured forces. It is found that the percentage of error is less than $4 \%$ which is accepted and the values are presented in Table 4 . This model can be effectively used to model machining parameters.

- Fig. 3 shows that the variation of surface roughness with axial depth of cut. It has been observed that the surface roughness increases with increase of axial depth of cut from $0.5 \mathrm{~mm}$ to $2 \mathrm{~mm}$. When depth of cut increases, the chip-thickness and the volume of material removal rate also increases. Hence the cutting force is increased. It affects the surface finish of the work piece machined.

- Fig. 4 shows that the variation of surface roughness with feed rate. The surface roughness increases with increase in the feed rate for the same cutting speed because of increased cutting forces. This is because the height of the peaks and the depth of the valleys of feed marks are proportional to the square of the feed per revolution. The nose radius has the least effect on surface roughness.

- From Fig 5, it has been observed that the surface roughness value decreases with increase in cutting speed. This could be due to the reduction of cutting forces at higher speed. The surface roughness is found to be lower at high cutting speed. It has been observed that while using MWCNT/water nanofluids as coolant, the surface roughness were reduced about $20 \%$ for the input parameters such as cutting speed, feed rate and depth cut. The variation of surface roughness is shown in fig $6 \& 7$.

- It has been identified that high cutting speed, low cutting feed rate and low axial depth of cut lead to better low cutting force and hence the surface roughness is reduced.

\section{CONCLUSION}

The experiments have been carried on a HASS machining center during machining EN 24 steel using a tungsten carbide cutter based on the DOE technique. It is found that using 
nanofluids as coolant, the cutting forces have been reduced marginally about 3-4 \%, whereas surface roughness improvement was observed as $20 \%$ when machining of steel EN 24. In order to improve the scope of work, an ANN model has been developed to predict cutting force by using experimentally measured values. The experimentally measured forces were compared with predicted values obtained using ANN model. The ANN model is found to be capable of better predictions of cutting forces within the range that they had been trained. The results of the ANN model indicate it to be much more robust and accurate in estimating the values of cutting forces. It is found that the depth of cut influences much more on surface roughness than other cutting parameters cutting speed and feed rate. The surface quality increases with increase in cutting speed and decrease in feed rate with decrease in depth of cut. This study provides a better position in continuing the tool monitoring system to enable an automated machining process for more efficient manufacturing in the future.

\section{REFERENCES}

[1] Abrari,F., Elbestawi.A. and Spence, A,D. (1998), "On the dynamics of Ball end milling: Modeling of cutting forces and stability analysis", International Journal of Machine Tools and Manufacture, Vol. 38, pp. 215-237

[2] Ginting, A and Nouari, M., (2007), "Optimal cutting conditions when dry end milling the aeroengine material Ti 6242S", Journal of Materials Processing Technology 184 , pp319-324.

[3] Lee S.K and Ko S.L (2001), "Improvements of the accuracy in the machining of a deep shoulder cut by end milling", Journal of Material Processing Technology, Vol. 111(1-3), pp. 244 -249.

[4] Palanisamy.P et.al, (2006) "Prediction of cutting force and temperature rise in the end-milling operation", Journal of Engineering Manufacture, I Mech Eng B , vol. 220 no. 10, pp. 1577 1587.

[5] Radhakrishnan.T and Uday Nandan, (2005)"Milling force prediction using regression and neural networks", Journal of Intelligent Manufacturing, 16, 93-102.

[6] Kaymakci, Z.M.Kilic, and Y.Altintas, "Unified cutting force model for turning, boring, drilling and milling operations", International Journal of Machine Tools and Manufacture, vol. 5455 , pp. 34-45, 2012

[7] Kovacic, M., Balic, J., Brezocnik, M., 2004. Evolutionary approach for cutting forces prediction in milling, Journal of Materials Processing Technology, Vol 155-156,pp1647 1652.

[8] Baskar , N., et.al (2006), "Selection of optimal machining parameters for multi-tool milling operations using a memetic algorithm", Journal of Materials Processing Technology 174, pp 239 $-249$.

[9] Palanisamy, Rajendran \& Shanmugasundara,(2008), "Modeling of tool wear and surface roughness in hard turning using regression and ANN, Int. Journal of machining and machinability of material, Vol. 4, pp 76-94

[10] Subramanian et.al (2013), “Optimization of Cutting Parameters for Cutting force in Shoulder Milling of Al7075-T6 Using Response Surface Methodology and Genetic Algorithm", Procedia Engineering 64, pp $690-700$

[11] Ganesh babu, B.,Selladurai, V and Shanmugam, R (2008), "Analytical modeling of cutting forces of end milling operation on aluminum silicon carbide particulate metal matrix composite material using response surface methodology, ARPN Journal of Engineering and Applied Sciences 3(2),pp5-18

[12] Liang wen et(al) (2012), "Application of Free Pattern Search on the surface roughness prediction in end milling, Evolutionary Computation (CEC), 2012 IEEE Congress, June, 10-15, DOI: 10.1109/CEC.2012.6256605.

[13] Siluveri.Sravanthi et al (2016), "Process parameters optimization for better surface[roughness and material removal rate of Aluminum alloy", "International Journal of Mechanical an production Engineering, Vol.4, Issue-10, Oct.-2016

[14] Mark A. Rubeo and Tony L. Schmit (2016), "Milling force modeling: a comparison of two Approaches", Procedia Manufacturing, Volume 5, , 2016, Pages 90-105

[15] Liu,X.W., Cheng, K., Webb, D and Luo, X.C (2002), “ Prediction of cutting force distribution and its influence on dimensional accuracy in peripheral milling”, International Journal of Machine Tools and Manufacture, Vol. 42, pp. 791-800.

[16] International Organization for Standardization ISO8688-2 (1989), first edition. Tool life testing in milling - part 2, end milling, Geneva 20, Switzerland.

[17] DOE - PC IV (1998) Software Reference Manual, Quality America Inc. 239 - 249.

Table 1 Process variables and their levels (Four Factors - Five Levels)

\begin{tabular}{|c|c|c|c|c|c|c|c|}
\hline \multirow{2}{*}{$\begin{array}{c}\text { Process } \\
\text { parameters }\end{array}$} & \multirow{2}{*}{ Units } & \multirow{2}{*}{$\begin{array}{c}\text { Notat } \\
\text { ion }\end{array}$} & \multicolumn{5}{|c|}{ Limits } \\
\cline { 4 - 8 } & & -2 & -1 & 0 & +1 & +2 \\
\hline $\begin{array}{c}\text { Cutting } \\
\text { speed }\end{array}$ & $\mathrm{m} / \mathrm{min}$ & $\mathrm{V} 1$ & 20 & 65 & 110 & 165 & 200 \\
\hline Feed & $\begin{array}{c}\mathrm{mm} / \mathrm{ro} \\
\mathrm{v}\end{array}$ & $\mathrm{f} 1$ & 0.05 & $\begin{array}{c}0.1 \\
0\end{array}$ & $\begin{array}{c}0.1 \\
5\end{array}$ & 0.20 & 0.25 \\
\hline $\begin{array}{c}\text { Depth of } \\
\text { cut }\end{array}$ & $\mathrm{mm}$ & $\mathrm{b} 1$ & 0.5 & $\begin{array}{c}0.7 \\
5\end{array}$ & 1.0 & 1.25 & 1.5 \\
\hline $\begin{array}{c}\text { Nose } \\
\text { radius }\end{array}$ & $\mathrm{mm}$ & $\mathrm{R} 1$ & 0.5 & $\begin{array}{c}0.7 \\
5\end{array}$ & 1.0 & 1.25 & 1.5 \\
\hline
\end{tabular}

Table 2. Design matrix values and Responses (Four factors - five levels)

\begin{tabular}{|c|c|c|c|c|c|c|c|c|c|c|}
\hline \multirow{3}{*}{$\begin{array}{c}\text { S1. } \\
\text { No }\end{array}$} & \multicolumn{3}{|c|}{ Input parameters } & \multicolumn{3}{c|}{$\begin{array}{c}\text { Cutting force, N } \\
\text { Measured }\end{array}$} & \multicolumn{2}{c|}{$\begin{array}{c}\text { Cutting force, Nicted from } \\
\text { PN }\end{array}$} \\
\cline { 2 - 13 } & C.S & Feed & DC & NR & Fx & Fy & Fz & Fx & Fy & Fz \\
\hline 1 & -1 & -1 & -1 & -1 & 135 & 200 & 46 & 132 & 198 & 45 \\
\hline 2 & 1 & -1 & -1 & -1 & 92 & 130 & 30 & 89 & 128 & 29 \\
\hline 3 & -1 & 1 & -1 & -1 & 142 & 206 & 47 & 140 & 203 & 46 \\
\hline 4 & 1 & 1 & -1 & -1 & 137 & 195 & 46 & 138 & 196 & 45 \\
\hline 5 & -1 & -1 & 1 & -1 & 186 & 264 & 63 & 185 & 263 & 62 \\
\hline 6 & 1 & -1 & 1 & -1 & 132 & 186 & 42 & 129 & 184 & 43 \\
\hline 7 & -1 & 1 & 1 & -1 & 201 & 281 & 67 & 198 & 279 & 65 \\
\hline 8 & 1 & 1 & 1 & -1 & 175 & 248 & 58 & 177 & 246 & 57 \\
\hline 9 & -1 & -1 & -1 & 1 & 163 & 235 & 54 & 162 & 233 & 54 \\
\hline 10 & 1 & -1 & -1 & 1 & 149 & 212 & 50 & 145 & 209 & 49 \\
\hline 11 & -1 & 1 & -1 & 1 & 157 & 219 & 49 & 156 & 216 & 50 \\
\hline 12 & 1 & 1 & -1 & 1 & 142 & 212 & 47 & 141 & 209 & 46 \\
\hline 13 & -1 & -1 & 1 & 1 & 178 & 258 & 59 & 175 & 254 & 58 \\
\hline 14 & 1 & -1 & 1 & 1 & 162 & 227 & 54 & 161 & 222 & 53 \\
\hline 15 & -1 & 1 & 1 & 1 & 198 & 281 & 67 & 196 & 275 & 68 \\
\hline 16 & 1 & 1 & 1 & 1 & 148 & 210 & 49 & 146 & 207 & 50 \\
\hline 17 & -2 & 0 & 0 & 0 & 122 & 170 & 41 & 125 & 167 & 40 \\
\hline 18 & 2 & 0 & 0 & 0 & 102 & 142 & 47 & 104 & 137 & 48 \\
\hline 19 & 0 & -2 & 0 & 0 & 89 & 124 & 31 & 88 & 126 & 30 \\
\hline 20 & 0 & 2 & 0 & 0 & 107 & 161 & 36 & 109 & 163 & 38 \\
\hline 21 & 0 & 0 & -2 & 0 & 116 & 160 & 39 & 115 & 162 & 40 \\
\hline 22 & 0 & 0 & 2 & 0 & 245 & 348 & 82 & 242 & 350 & 84 \\
\hline 23 & 0 & 0 & 0 & -2 & 85 & 118 & 28 & 83 & 116 & 27 \\
\hline 24 & 0 & 0 & 0 & 2 & 139 & 203 & 47 & 137 & 202 & 46 \\
\hline 25 & 0 & 0 & 0 & 0 & 123 & 178 & 41 & 121 & 176 & 42 \\
\hline 26 & 0 & 0 & 0 & 0 & 127 & 176 & 42 & 128 & 176 & 41 \\
\hline 27 & 0 & 0 & 0 & 0 & 126 & 178 & 42 & 124 & 176 & 42 \\
\hline 28 & 0 & 0 & 0 & 0 & 128 & 192 & 41 & 127 & 190 & 42 \\
\hline 29 & 0 & 0 & 0 & 0 & 128 & 193 & 41 & 126 & 191 & 41 \\
\hline 30 & 0 & 0 & 0 & 0 & 128 & 192 & 42 & 126 & 189 & 41 \\
\hline 31 & 0 & 0 & 0 & 0 & 127 & 193 & 42 & 125 & 189 & 43 \\
\hline 32 & 0 & 0 & 0 & 0 & 127 & 193 & 43 & 126 & 193 & 44 \\
\hline
\end{tabular}




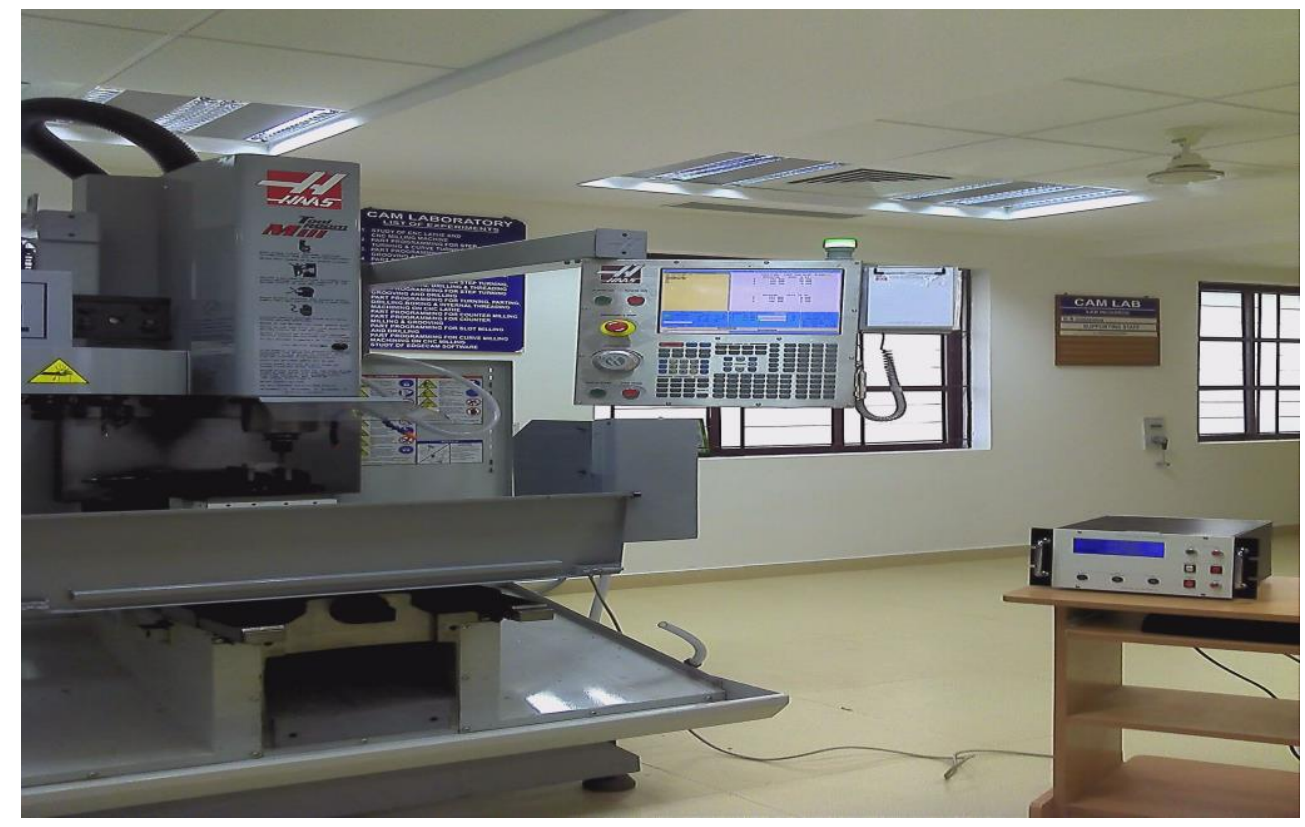

Fig.1. Experimental setup - Syscon tool dynamometer connected with HASS Vertical Machining Centre

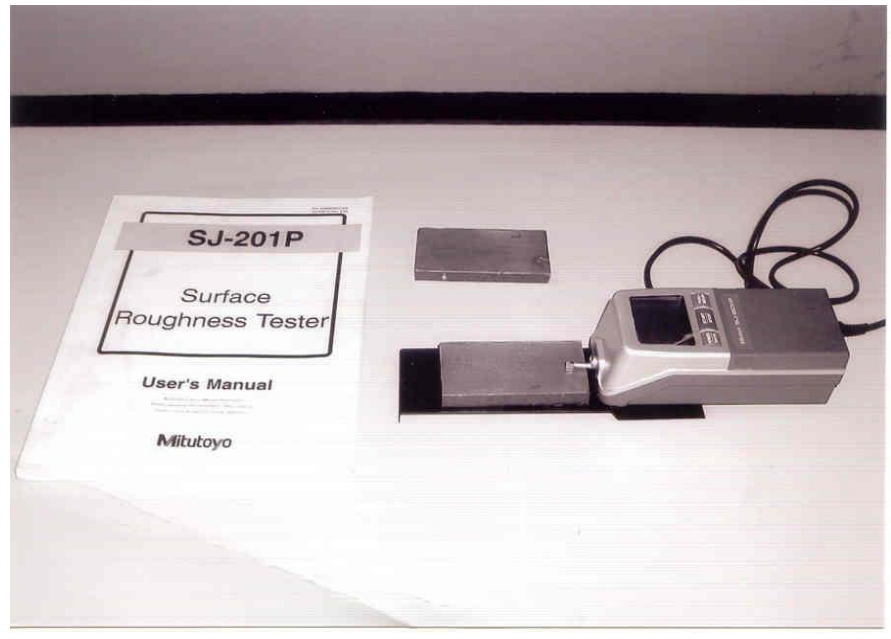

Fig. 2 The surface roughness tester used to measure

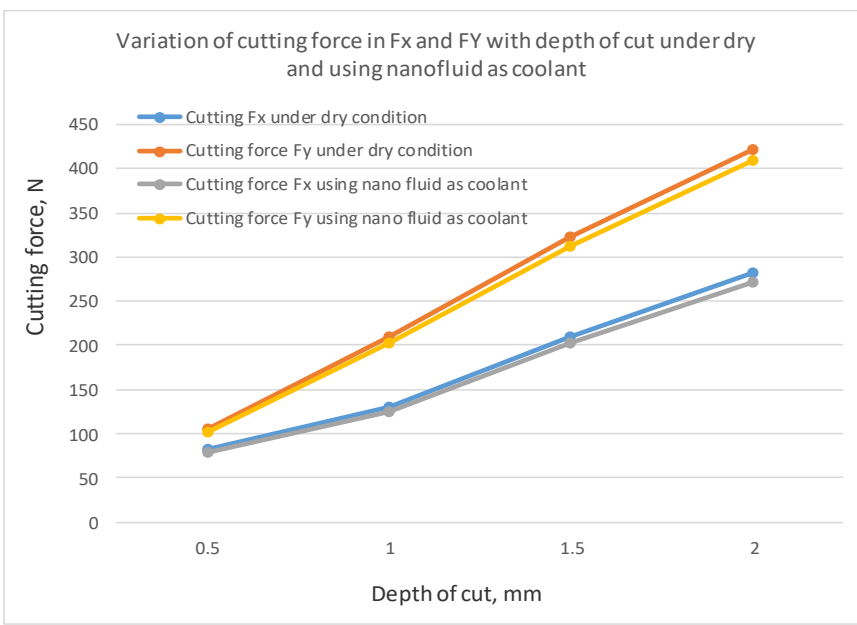

Fig. 3 The Cutting force variation (Fx \& Fy) with DOC 
Cutting force ( $F x$ \& Fy) variation with Feed rate under dry condition and using nano fluid as coolant for constant depth of cut of $1.5 \mathrm{~mm}$

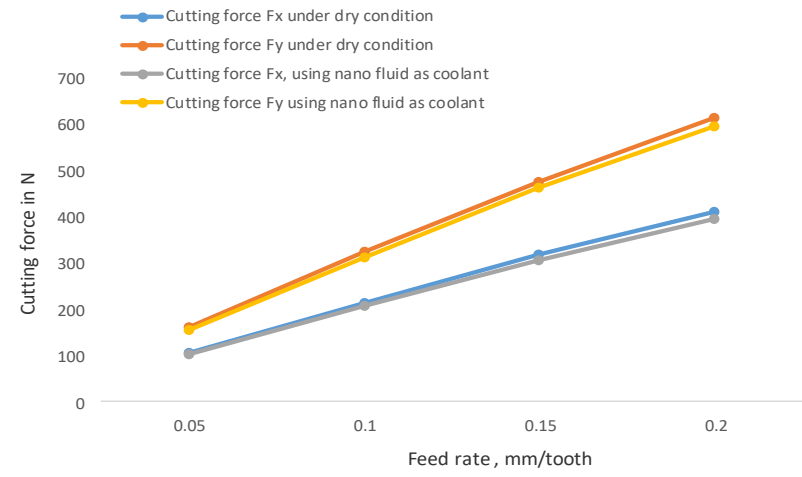

Fig. 4 The cutting force variation (Fx \& Fy) with feed rate

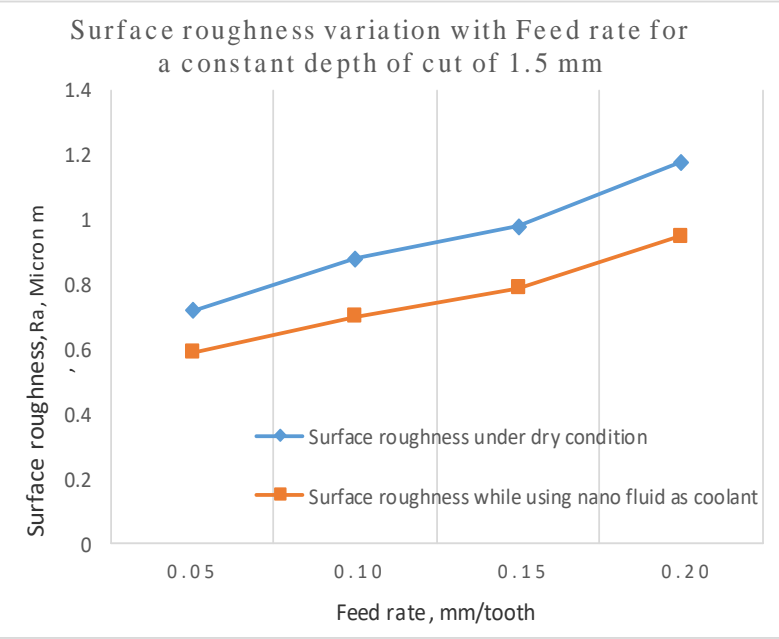

Fig. 6. The variation of surface roughness with feed rate

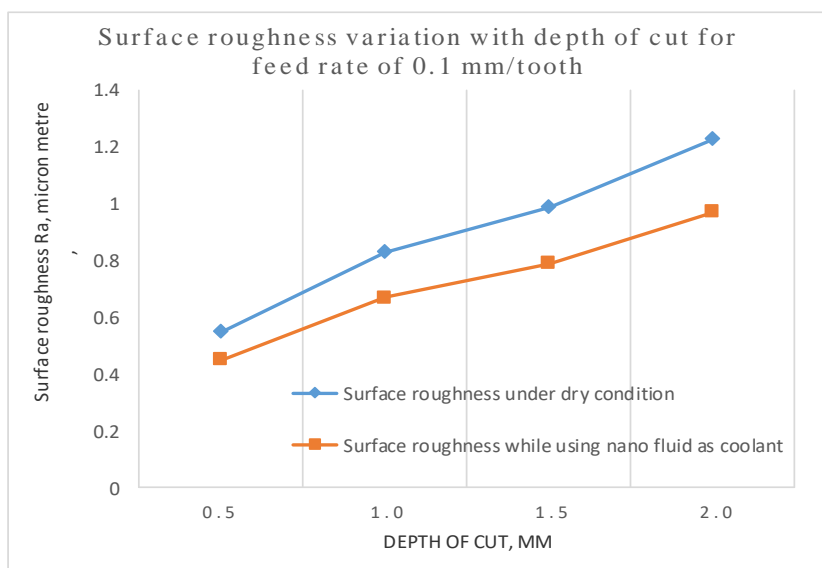

Fig. 5 The variation of surface roughness with DOC

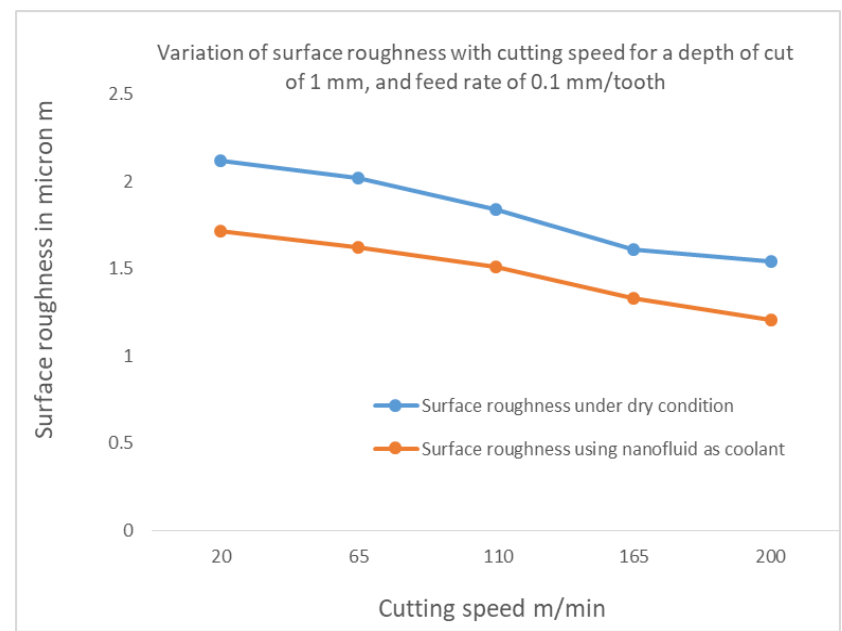

Fig.7 The surface roughness with cutting speed 